the assessment and management of pain was vague and no detail was given as to how health professionals should perform these tasks. There was no reference to pain intensity, location or emotion. There were several problematic conceptual issues in the way pain was presented, with pain mostly portrayed either in the context of inflammatory or non-inflammatory pain and rarely in the context of both. Musculoskeletal pain was also positioned as a 'somatic' symptom, potentially conveying an interpretation of pain as being psychologically mediated. Conclusion: Training for healthcare professionals in paediatric rheumatology would benefit from updates informed by contemporary pain theories and evidence-based practices. This is key to ensuring that children and young people with chronic pain receive effective pain care from tertiary care services focused on treating musculoskeletal disease.

Table 1. Documents and pain terms identified

\begin{tabular}{|c|c|c|c|}
\hline Profession & Title & $\begin{array}{l}\text { Organisations, } \\
\text { year. }\end{array}$ & $\begin{array}{l}\% \text { of document } \\
\text { covered by } \\
\text { pain terms }\end{array}$ \\
\hline $\begin{array}{l}\text { Doctors } \\
\text { Doctors } \\
\text { Doctors } \\
\text { Doctors } \\
\text { Doctors }\end{array}$ & $\begin{array}{l}\text { Generic syllabus level } 1 . \\
\text { Generic syllabus level } 2 . \\
\text { Generic syllabus level } 3 . \\
\text { Paediatric rheumatology level } 3 \text {. } \\
\text { Competencies for the special interest mod- } \\
\quad \text { ule in paediatric rheumatology }\end{array}$ & $\begin{array}{l}\text { RCPCH, } 2018 . \\
\text { RCPCH, } 2018 . \\
\text { RCPCH, } 2018 . \\
\text { RCPCH, } 2018 . \\
\text { RCPCH, } 2014 .\end{array}$ & $\begin{array}{l}0.14 \% \\
0.14 \% \\
0.06 \% \\
0.48 \% \\
0.43 \%\end{array}$ \\
\hline $\begin{array}{l}\text { Nurses } \\
\text { Nurses }\end{array}$ & $\begin{array}{l}\text { Competencies for rheumatology nurses. } \\
\text { Competencies for clinical nurse specialists/ } \\
\text { advanced nurse practitioners. }\end{array}$ & $\begin{array}{l}\text { RCN, } 2020 . \\
\text { BSPAR, } 2014 .\end{array}$ & $\begin{array}{l}0.05 \% \\
0.29 \%\end{array}$ \\
\hline $\begin{array}{l}\text { Nurses } \\
\text { Allied Health } \\
\text { Professionals } \\
\text { (AHPs) }\end{array}$ & $\begin{array}{l}\text { Role of the paediatric rheumatology nurse. } \\
\text { Competencies for AHPs }\end{array}$ & $\begin{array}{l}\text { SPARN, } 2016 . \\
\text { BSPAR, } 2019 .\end{array}$ & $\begin{array}{l}0 \% \\
0.73 \%\end{array}$ \\
\hline
\end{tabular}

Disclosure of Interests: None declared

DOI: 10.1136/annrheumdis-2021-eular.210

\section{POS1491-HPR MENTAL HEALTH OUTCOMES AMONG HEALTH CARE WORKERS DURING THE CORONAVIRUS-19 PANDEMIC}

O. Hamdi ${ }^{1}$, M. Sellami ${ }^{1}$, S. Miladi ${ }^{1}$, A. Fazaa ${ }^{1}$, L. Souabni ${ }^{1}$, K. Ouenniche $^{1}$, S. Kassab ${ }^{1}$, S. Chekilii', K. Ben Abdelghani ${ }^{1}$, A. Laatar ${ }^{1} .{ }^{1}$ Mongi Slim Hospital, Rheumatology, Tunisia, Tunisia

Background: The coronavirus-19 (COVID-19) pandemic is having negative effects on societies' mental health, particularly health care workers who are exposed to tremendous psychological stress.

Objectives: To assess the magnitude of mental health outcomes among health care workers treating patients exposed to COVID-19.

Methods: This cross-sectional study collected demographic data and mental health measurements from health workers in different hospitals using an online questionnaire. Participants were also asked to complete the 9-item Patient Health Questionnaire (PHQ-9), the 7-item Insomnia Severity Index (ISI), and the 7-item Generalized Anxiety Disorder scale (GAD-7). The total scores of these measurement tools were interpreted as follows: PHQ-9 normal (0-4), mild (5-9), moderate (10-14), and severe (15-21) depression; ISI normal (0-7), mild (8-14), moderate (15-21), and severe (22-28) insomnia; GAD-7 normal (0-4), mild (5-9), moderate (10-14), and severe (15-21) anxiety.

Results: A total of 155 health care workers with a mean age of $31.3 \pm 25$ years [26-45] and a sex-ratio of 0.3 completed the online questionnaire. All participants were directly engaged in diagnosing, treating, or caring for patients with or suspected to have COVID-19. Participants were divided into two groups: $79 \%$ medical $61 \%$ doctors in training and $18 \%$ hospital doctors) and $21 \%$ paramedical staff. Twenty-two participants (14.2\%) had a chronic disease and $21(13.5 \%)$ had a history of depression. Nineteen (12.2\%) of the participants were infected with COVID-19, 4 of whom contracted the infection in the hospital $50 \%$ during October 2020). A statement to the department of occupational medicine was made in $70 \%$ of cases. Ninety-one percent of the participants were fit for treating patients with COVID-19. The mean number of nightshifts in the COVID unit per month was 5.3. The mean number of hours of work in the COVID unit was 5 hours per day, 36 hours per week, and 62 hours per month. An increase in workload compared to the pre-epidemic was noted in $62.9 \%$ of cases. Thirteen percent of participants experienced the same anxiety level as the first time of taking care of COVID patients while $65 \%$ were rather at ease compared to the first time. Forty-seven percent of participants felt the need for psychological support and $16.7 \%$ of whom had consulted a psychiatrist. Participants were diagnosed with depression (9 cases), anxiety (13 cases), and burn-out ( 3 cases). The prescribed treatment was: antidepressants ( 5 cases), anxiolytic (10 cases), and psychotherapy (12 cases). Mild depression was detected in $13 \%$ of cases, moderate depression in $4 \%$ of cases, and severe depression in $2 \%$ of cases. Mild insomnia was detected in $41 \%$ of cases, moderate insomnia in $14 \%$ of cases, and severe insomnia in $9 \%$ of cases. As for anxiety, 33\% of participants suffered from mild anxiety, $14 \%$ moderate anxiety, and $5 \%$ severe anxiety.

Conclusion: Participants reported experiencing psychological burden and a high rate of anxiety, depression, and insomnia. It is important to protect health care workers and to promote mental well-being to survive this pandemic.
Disclosure of Interests: None declared

DOI: 10.1136/annrheumdis-2021-eular.783

\section{POS1492-HPR EVALUATION OF A VIRTUAL REALITY-BASED APPLICATION TO EDUCATE HEALTHCARE PROFESSIONALS AND MEDICAL STUDENTS ABOUT INFLAMMATORY ARTHRITIS}

P. Klemm 1 , A. Kleyer ${ }^{2}$, K. Tascilar², L. Schuster ${ }^{2}$, T. Meinderink², F. Steiger ${ }^{2}$, U. Lange ${ }^{1}$, U. Müller-Ladner ${ }^{1}$, J. Knitza ${ }^{2}$, P. Sewerin ${ }^{3}$, J. Mucke ${ }^{3}$, A. Pfeil ${ }^{4}$, G. Schett ${ }^{2}$, F. Hartmann ${ }^{2}$, A. Hueber ${ }^{5}$, D. Simon ${ }^{2}{ }^{1}{ }^{3}$ Justus-Liebig University Gießen, Campus Kerckhoff, Department of Rheumatology, Immunology, Osteology and Physical Medicine, Gießen, Germany; ${ }^{2}$ Universitätsklinikum Erlangen, Department of Internal Medicine 3, Rheumatology and Immunology, Erlangen, Germany, Erlangen, Germany; ${ }^{3}$ Heinrich Heine University Düsseldorf, Department and Hiller Research Unit for Rheumatology, Düsseldorf, Germany; ${ }^{4}$ Jena University Hospital - Friedrich Schiller University, Department of Internal Medicine 3, Jena, Germany; ${ }^{5}$ Sozialstiftung Bamberg, Sektion Rheumatologie, Bamberg, Germany

Background: Inflammatory arthritides (IA), such as rheumatoid arthritis or psoriatic arthritis, are disorders that can be difficult to comprehend for health professionals and students in terms of the heterogeneity of clinical symptoms and pathologies. New didactic approaches using innovative technologies such as Virtual Reality (VR) applications could be helpful to demonstrate disease manifestations as well as joint pathologies in a more comprehensive way. However the potential of using a VR education concept in IA has not yet been evaluated. Objectives: We evaluated the feasibility of a VR application to educate healthcare professionals and medical students about IA.

Methods: We developed a VR application using IA patients data as well as two- and three-dimensional visualized pathological joints from X-ray and computed tomography generated images (1). This VR application (called Rheumality) allows the user to interact with representative arthritic joint and bone pathologies of IA patients (Figure $1 \mathrm{~A}, \mathrm{~B}$ ). In a consensus meeting an online questionnaire was designed to collect basic demographic data (age, sex), profession of the participants, and their feedback on the general impression, knowledge gain and potential areas of application of the VR application. The VR application was subsequently tested and evaluated by healthcare professionals (physicians, researchers, and other healthcare professionals) and medical students at predefined events (two annual rheumatology conferences and academic teaching seminars at two sites in Germany). Results: 125 individuals participated in this study (56\% female, $43 \%$ male, $1 \%$ non-binary). $59 \%$ of the participants were between $18-30$ years of age, $18 \%$ between $31-40$, $10 \%$ between $41-50,8 \%$ between $51-60$ and $5 \%$ were between $61-70$. Of the participants, 50 were physicians, five researchers and four other health care professionals, the remaining were medical students (66). The participants rated the application as excellent (Figure 1 C, D), the mean rating of the VR application was 9.0/10 (SD 1.2) and many participants would recommend the use of the application, with a mean recommendation score of 3.2/4 (SD 1.1). A large majority stated that the presentation of pathological bone formation improves the understanding of the disease (120 out of $125(96 \%))$.

Conclusion: The data show that IA-targeting innovative teaching approaches based on VR technology are feasible. The use of VR applications enables a disease-specific knowledge visualization and may add a new educational pillar to conventional educational approaches.

REFERENCES:

[1] Kleyer A et al. Z Rheumatol 78, 112-115 (2019)
A
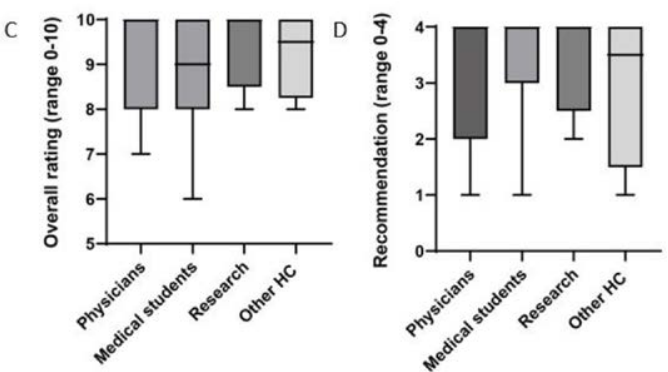

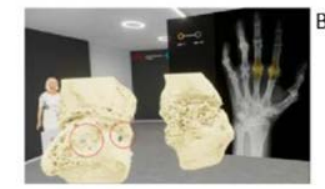


Two- and three-dimensional visualized pathological joints from X-ray and computed tomography generated images in a patient with long-standing (inadequately treated) RA (A) and a patient with early RA (B). Overall rating (range $0-10$ ) on the VR application divided into four different professional subgroups (C); recommendations of VR application in the four different professional subgroups (D). HC, health care professionals; Boxplot explanation: Crossbars represent medians, whiskers represent 5-95 percentiles (points below the whiskers are drawn as individual points), box always extends from the 25th to 75th percentiles (hinges of the plot).

Disclosure of Interests: Philipp Klemm Consultant of: Lilly Deutschland GmbH, Arnd Kleyer Speakers bureau: Lilly Deutschland $\mathrm{GmbH}$, Consultant of: Lilly Deutschland $\mathrm{GmbH}$, Grant/research support from: Lilly Deutschland $\mathrm{GmbH}$, Koray Tascilar: None declared, Louis Schuster: None declared, Timo Meinderink: None declared, Florian Steiger: None declared, Uwe Lange: None declared, Ulf Müller-Ladner: None declared, Johannes Knitza Speakers bureau: Lilly Deutschland GmbH, Philipp Sewerin Speakers bureau: Lilly Deutschland GmbH, Paid instructor for: Lilly Deutschland $\mathrm{GmbH}$, Johanna Mucke Consultant of: Lilly Deutschland $\mathrm{GmbH}$, Alexander Pfeil Speakers bureau: Lilly Deutschland GmbH, Paid instructor for: Lilly Deutschland $\mathrm{GmbH}$, Consultant of: Lilly Deutschland $\mathrm{GmbH}$, Georg Schett: None declared, Fabian Hartmann Consultant of: Lilly Deutschland $\mathrm{GmbH}$, Axel Hueber Consultant of: Lilly Deutschland GmbH, Grant/ research support from: Lilly Deutschland $\mathrm{GmbH}$, David Simon Speakers bureau: Lilly Deutschland $\mathrm{GmbH}$, Paid instructor for: Lilly Deutschland $\mathrm{GmbH}$, Consultant of: Lilly Deutschland $\mathrm{GmbH}$, Grant/research support from: Lilly Deutschland $\mathrm{GmbH}$

DOI: 10.1136/annrheumdis-2021-eular.1452

\section{POS1493-HPR IMPACT OF THE EULAR HCP CORE COMPETENCIES ON RHEUMATOLOGY PHYSIOTHERAPISTS INTHE UK: SURVEY RESULTS}

W. J. Gregory ${ }^{1,2}$, S. Burchett ${ }^{3}$, C. Mccrum ${ }^{4,5} .{ }^{1}$ Salford Royal NHS Foundation Trust, Rheumatology Directorate, Manchester, United Kingdom; ${ }^{2}$ Manchester Metropolitan University, Department of Health Professionals; Faculty of Health, Psychology and Social Care, Manchester, United Kingdom; ${ }^{3}$ East Sussex Healthcare NHS Trust, Information Management and Performance, Hastings, United Kingdom; ${ }^{4}$ East Sussex Healthcare NHS Trust, Physiotherapy Department, Hastings, United Kingdom; ${ }^{5}$ University Of Brighton, Research Centre for Healthcare Professionals, Brighton, United Kingdom

Background: A European Alliance of Associations for Rheumatology (EULAR) initiative in 2019 saw the first-ever publication of Core Competencies for Health Care Professionals (HCPs) working in Rheumatology (Edelaar et al 2019). This document sets the tone for how HCPs in Rheumatology should be working. One of the listed research agenda items created as a part of this project was to define discipline-specific competencies related to each of the HCPs unique roles in the multidisciplinary team.

Objectives: In response to this call for discipline-specific application, a recent national survey of physiotherapists working in rheumatology in the UK included a section looking at the comfort these clinicians feel in the day-to-day application of these Core Competencies.

Methods: In late 2019, an internet-based survey was emailed, and shared via other digital platforms, aiming to target all UK-based rheumatology physiotherapists. Other areas were covered and have been published (Gregory, Burchett and McCrum 2021), but there are unpublished data from Question 8 on this survey which involved listing the EULAR HCP Core Competencies and asking responders to rate on a 5-point Likert scale their comfort with these statements in relation to their day-to-day practice.

Results: Ninety-seven UK-based physiotherapists working at least some of their job in rheumatology completed the survey. Overall the EULAR HACP core competency statements with the highest scores were statements 2 and 5 ; those statements with the lowest comfort response were statements 4 and 6 .

Statement 2 relates to assessment and statement 5 to non-pharmacological management; it is in line with the traditional physiotherapy job role that these are the two areas identified by survey responders as their strongest areas.

Statement 4 relates to pharmacological management, and as this is not a formal part of expected specialist rheumatology physiotherapist job role at banding levels below band 8, this result was lower level of comfort probably to be expected. Statement 6 relates to patient education and whilst this is clearly a big part of the physiotherapist role, we expect the lower score here represents respondents awareness that broader disease education may sit better with other members of the rheumatology multi-disciplinary team.

Conclusion: Written for all HCPs, the competency statements do show less comfort on this survey of physiotherapists with regards to less profession-specific statements, namely medication management and disease education. Team working means these areas will be picked up by other rheumatology HCPs.

Generally there is a good amount of familiarity with and comfort in application of these new core competencies. An alternative conclusion is that the EULAR working group creating the competencies achieved a strong understanding of the HCP roles and the competencies are hence seen to fit well in this survey. As per the concluding statements of the 2019 EULAR core competencies document, there does remain a requirement to work on profession specific competencies in rheumatology.

REFERENCES:

[1] Edelaar L, Nikiphorou E, Fragoulis GE, et al. 2019 EULAR recommendations for the generic core competences of health professionals in rheumatology. Annals of the Rheumatic Diseases 2020;79:53-60.

[2] Gregory, W.J., Burchett, S. and McCrum, C. (2021), National survey of the current clinical practices of the UK rheumatology physiotherapists: A short report. Musculoskeletal Care. https://doi.org/10.1002/msc.1516

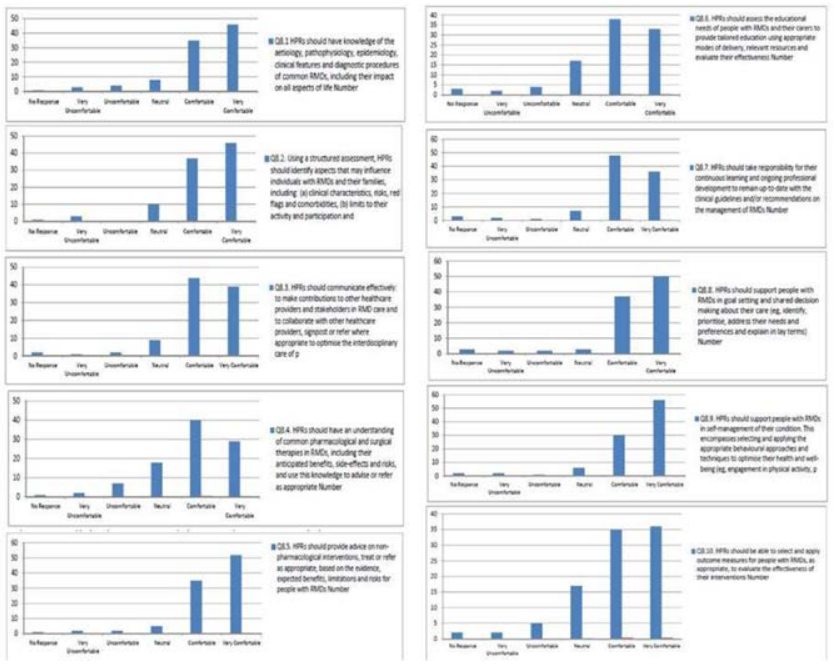

Disclosure of Interests: William J. Gregory Speakers bureau: Speaker fees from Novartis and Abbvie., Consultant of: Advisory boards for Pfizer and Novartis., Sharon Burchett: None declared, Carol McCrum Speakers bureau: Speaker fees from Novartis

DOI: 10.1136/annrheumdis-2021-eular.2808

\section{HPR Interdisciplinary research}

\section{POS1494-HPR THE COLLABORATION OF RHEUMATOLOGY- DERMATOLOGY IN THE EVALUATION OF RHEUMATIC DISEASES PATIENTS: EXPERIENCE IN A UNIVERSITY HOSPITAL}

G. Figueroa-Parra ${ }^{1}$, A. Moreno-Salinas ${ }^{1}$, C. M. Gamboa-Alonso ${ }^{1}$, M. A. Villarreal-Alarcón ${ }^{1}$, D. Á. Galarza-Delgado ${ }^{1}{ }^{1}$ Hospital Universitario Dr. José Eleuterio González, Universidad Autónoma de Nuevo León, Servicio de Reumatología, Monterrey, Mexico

Background: Dermatological manifestations are not rare in patients with rheumatic diseases (RD). Multidisciplinary management and direct interaction between these disciplines are essential. According to Dermatology-Rheumatology clinics, most diagnoses evaluated are systemic lupus erythematosus (SLE) and rheumatoid arthritis (RA), with dermatitis being the most common manifestation. It is important to be aware that skin problems in RD patients are not always related to the underlying condition(1). Nowadays, there is significant evidence to support the manifold advantages of the joint dermatology-rheumatology clinics, including improved quality of care for patients and multidisciplinary training for new physicians(2). This ongoing trend is intended to highlight the important interaction between specialties that treat overlapping conditions, and it has been incorporated in academic health centers to give a comprehensive approach to patients.

Objectives: Our purpose was to describe the collaboration between the Rheumatology and Dermatology services during the evaluation of RD patients.

Methods: An observational, retrospective study was performed in the Rheumatology Service of the University Hospital "Dr. Jose Eleuterio Gonzalez" in Monterrey, Mexico, between March 2019 and February 2020. All the patients with a Rheumatology or Dermatology consultation requested were included (hospitalized and outpatients). Demographic (age, gender, baseline diagnosis), the reason for consultation, specialty requested, type of treatment, final diagnoses, and agreement in final diagnosis were registered. Results are shown in descriptive statistics. 